\title{
Oninvestigation on Community Employment Intention of Medical Gradu- ates and its Influencing Factors
}

\author{
Wei Bo ${ }^{1, *}$, Xie Hui ${ }^{1}$ and Xia Ronghai ${ }^{2}$ \\ ${ }^{I}$ North China University of Science and Technology, Tangshan Hebei 063009, China; ${ }^{2}$ HebeI Datang International \\ Fengrun Thermal Power CO., LTD, Fengrun, Hebei 064000, China
}

\begin{abstract}
Objective Investigation on community employment intention of medical graduates and its influencing factors, provides the basis for the relevant departments to formulate policies. Method In 2014 May, the author selected 1120 students in 2009-2013 level clinical, nursing, pharmacy, medical image, oral, traditional Chinese medicine from a medical college of Tangshan City. Using the self-made questionnaire survey, the content includes the basic situation, basic employment expectations of medical students, medical student community employment intention. Result In 1108 Medical College students investigated, there are 26.1\% (289) medical students choose "willing to accept "the work of Community Health Service Center (station), there are 71\% (787) medical students choose "there is no way can, also accept", there are 2.9\% (32) medical students choose " not accept resolutely". In various impediment factors of medical students in the community employment, the first three factors are the highest percentage is "community treatment and security is low" $(98.1 \%)$, " less opportunities of training, continuing education" $(86.3 \%)$, "work environment in community is poor" $(82.1 \%)$. Conclusion The government should increase construction dynamics of the community health service center (station), the school should strengthen the introduction and propaganda work of the community health service center (station), medical students should understand the severe employment situation, reduce the expected value of employment, and establish a correct concept of employment.
\end{abstract}

Keywords: Community employment intention, influencing factors, medical students.

\section{INTRODUCTION}

With the popularization of higher education in China, the total amount of the medical students is increasing year by year, the employment difficulty for medical graduates has become increasingly prominent. However, most parts of our country community health service center (station) is facing a serious shortage of talent, which is also one of the important factors hindering the development of the community health service in China. In March 2009, the Chinese government issued "The Central Committee of the Communist Party of the Opinions of the State Council on Deepening the Reform of Medical Health System" (found [2009] no. 6), and put forward formulate preferential policies to encourage excellent medical personnel to the city community service [1]. In this context, the author conducted a questionnaire survey of students in a medical college in May 2014, to understand the factors of medical students at present community employment intention and influence, provides the reference for the government, hospitals and schools to make the relevant policy measures.

2009-2013 level clinical, nursing, pharmacy, medical image, traditional Chinese medicine oral, all students in a medical college from Tangshan City 1120 people surveyed.

This research used the anonymous self-administered questionnaire and interview.
Survey content mainly involves three aspects: (1) the basic situation of medical students, including gender, professional, grade and political landscape, students and family economic conditions, etc.; (2) the basic expectations of medical students to employment, including employment situation, employment unit nature of expectation and salary expectations; (3) medical students community employment intention, including the cognition of grass-roots employment, are you willing to work to community employment, length of expectations, prompting and hinder the medical students to the various factors of community employment, at the grassroots level to the school career guidance's comments and Suggestions, etc.

Interview the employment office teacher, understand the current employment guidance work, understand the basic situation of our hospital in recent three years the employment of graduates and community employment.

This research first on a small scale has made the preliminary investigation, according to the preliminary investigation results to adjust and perfect questionnaire. Second communicate with departments of teachers, using random cluster sampling method, each professional each grade choose 40 people as the object of investigation. Finally the student cadres as investigators, carries on the training, to ensure that the questionnaire is real and effective.

Excel software was used to input data, using SPSS17.0 statistical analysis. According to the characteristics and categories of data, take statistical methods such as descriptive analysis, multiple linear regression analysis. 


\section{RESULT AND DISSCUSS}

\subsection{The Basic Situation of Medical Students}

In 1108 copies of effective questionnaire (recovery rate $98.9 \%)$, 432 males $(39 \%), 676$ females $(61 \%)$; clinical medical professional 197 people (17.8\%), 159 (14.3\%) nursing, pharmacy professional 158 people $(14.2 \%)$, medical imaging specialty of 198 people (17.8\%), 197 (stomatology 17.8\%), Chinese medicine professional 199 people (18.1\%); low grade (a) 238 people $(21.5 \%$ ), grade (two, three) 476 people (43\%), high grade (four, five); 394 (35.5\%) students, rural students 455 people $(41.10 \%)$ non rural students, 653 people $(58.9 \%)$; poor students (still have difficulty using a variety of ways but raise tuition) 108 people $(9.7 \%)$, non impoverished people $(90.3 \%)$.

\subsection{Basic Expectations of Medical Students to Employ- ment}

According to the survey, $56.0 \%$ (620 people) of medical students think that "the current severe employment situation, it is difficult to obtain employment", $25.0 \%$ (277) of the medical students think "can well the current employment situation, employment", only $19.0 \%$ (211 people) of the medical students think that "the current employment situation is good, easy to obtain employment"; 97.6\% (1081 people) of the medical students wish to state organs, institutions and public hospital work, only $2.4 \%$ (27) people want to work for a private hospitals, clinics, or joint ventures; Wage and consumption level, hebei province as the reference, $65.1 \%$ (721 people) of the medical students hope that 2000 4000 yuan a month, $11.3 \%$ (125 people) of the medical students hope to under 2000 yuan a month, 23.6\% (262 people) of the medical students hope to more than 4000 yuan a month. Research shows that, although most medical students think severe employment situation at present, but their employment expectations are not low.

\subsection{The Grass-roots Employment Intention of Medical Students}

\subsubsection{On the Grass-roots Employment Cognition}

When asked what is the grass-roots employment, only $13 \%$ (144) medical students choose "know, very clear", 78\% (864) medical students choose "heard, not too clear" 9\% (100) medical students choose "not heard of, don't know". When asked "do you know the national levels of government policy related to the college students employment?" When, only 7.9\% (87) medical students choose "very aware", 42\% (465) medical students choose to "understand", 50.1\% (565) medical students choose "do not understand". When asked "do you understand the community health service center (station)?" When there are 27\% (299), medical students choose "very aware", 45.8\% (508) medical students choose to "understand", 27.2\% (301) medical students choose "do not understand".

\subsubsection{The Community Employment Intention}

Investigation shows, only $6.8 \%$ (75) of medical students after graduation preferred to community health service center (station) employment. When asked "if more difficult to enter your ideal work units, whether you are willing to community health service center (station) employment?" When there are $26.1 \%$ (289), medical students choose "willing to accept", $71 \%$ (787) medical students choose "there is no way can also accept", 2.9\% (32) medical students choose "determined not to accept the". When asked "if in Community Health Service Center (station), are you willing to work long hours?" When there are $26.3 \%$ (292), medical students choose "view work, real life circumstances", 69\% (764) medical students choose "no intention of long time work at the grassroots level, only to increase the work experience", only $4.7 \%$ (52) medical students choose "stay community work for a long time".

According to the survey, in making medical students to the various factors of community employment, the highest percentage of the first three factors were "can temporarily alleviate employment pressure" (95.4\%), "grassroots can exercise more people" (87.8\%) and "preferential policies to attract" $(67.8 \%)$. The results are shown in Fig. (1). In the way of medical students to the community employment of various factors, the highest percentage of the first three factors were "community treatment is low, poor security" (98.1\%), less chance "training, further education, continuing education and so on" $(86.3 \%)$ and "poor working environment of the community" (82.1\%). The results shown in Fig. (2).

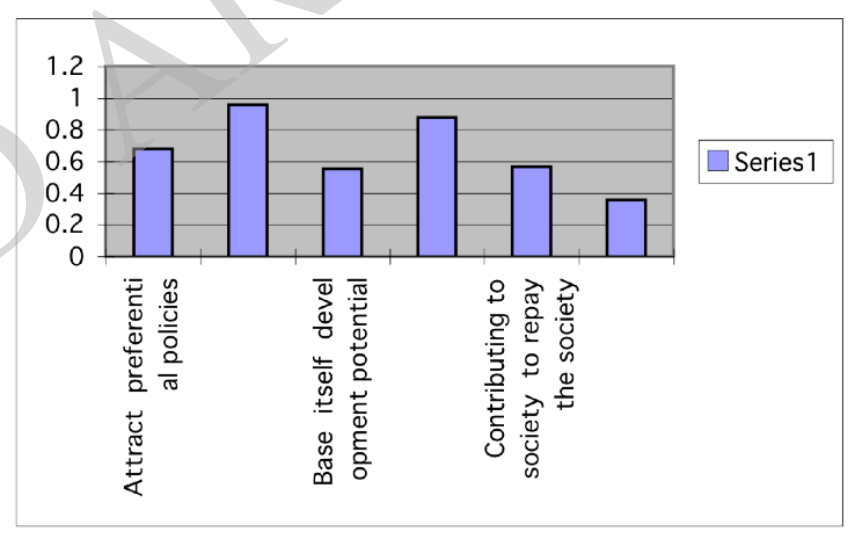

Fig. (1). The percentage of the factors to promote the employment of medical students into the community.

\subsubsection{Evaluation of School on Grass-roots Employment Guidance}

When asked "how do you think of the school in terms of medical students' employment at the grass-roots level of service", only $3.0 \%$ (33) of the medical students choose "it is very good, very helpful", $15.0 \%$ (166) of the medical students choose "general, some help to me," and 82.0\% (909 people) medical students choose "it is not good, no help to me."

\subsubsection{Medical Undergraduates Grass-roots Employment Intention of Multiple Linear Regression Analysis}

Community employment intention composite scores as the dependent variable, the single factor analysis of variance $(\mathrm{a}=0.01)$, with "professional, grade and students, whether for poor students, employment expectations, salary expectations, the degree of grass-roots employment policy understanding, understanding of community health service center (station), school employment guidance at the grass-roots 


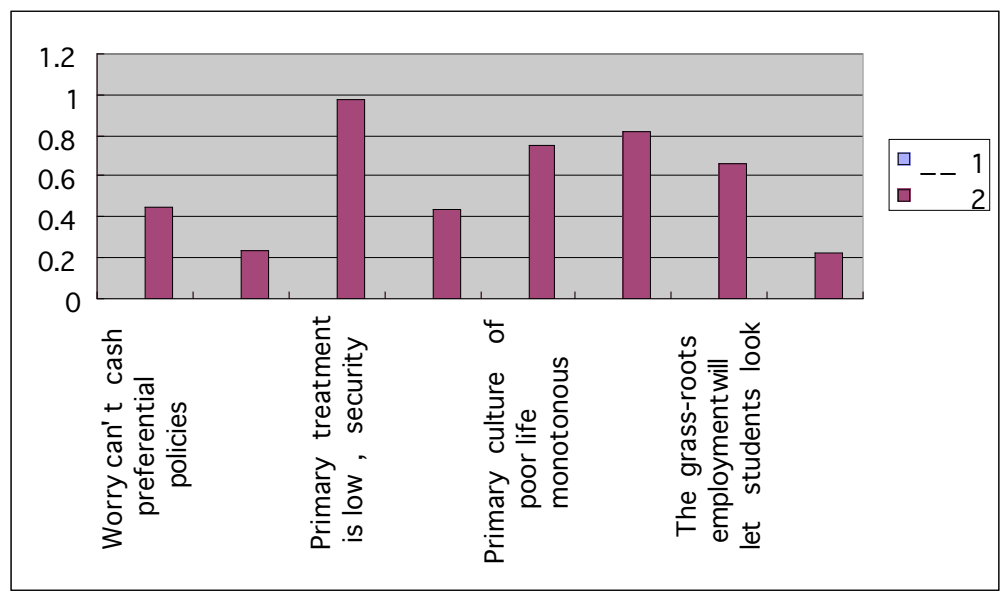

Fig. (2). The percentage of the factors to hinder the employment of medical students into the community.

Table 1. Factors that may affect the willingness of community employment assignment.

\begin{tabular}{|c|c|c|}
\hline Variable & Name & Definition and Assignment \\
\hline $\mathrm{X} 1$ & Grade & Low- grade $=1$, Middle Grade $=2$, High grade $=3$ \\
\hline $\mathrm{X} 2$ & Major & Clinical professional $=1$, Non-clinical professional $=2$ \\
\hline $\mathrm{X} 3$ & Employment judge & Severe $=1$, Fair $=2$, Good $=3$ \\
\hline $\mathrm{X} 4$ & Whether for poor students & $\mathrm{Yes}=1, \mathrm{No}=2$ \\
\hline $\mathrm{X} 5$ & origin of student & Rural students $=1$, Non-rural students $=2$ \\
\hline $\mathrm{X} 6$ & Salary expectation & $\begin{array}{c}\text { Less than } 2000 \text { yuan }=1,2000-4000 \text { yuan }=2 \text {, More than } 4000 \\
\text { yuan }=3\end{array}$ \\
\hline $\mathrm{X} 7$ & Basic knowledge of the employment policy & $\begin{array}{c}\text { Understood extremely }=1 \text {, Understand some }=2 \text {, Don't under- } \\
\qquad \text { stand }=3\end{array}$ \\
\hline $\mathrm{X} 8$ & Understanding of community health service center (station) & $\begin{array}{c}\text { Understood extremely }=1 \text {, Understand some }=2 \text {, Don't under- } \\
\qquad \text { stand }=3\end{array}$ \\
\hline $\mathrm{X} 9$ & $\begin{array}{l}\text { Degree of grass-roots employment guidance with the help of the } \\
\text { school }\end{array}$ & Very helpful $=1$, some help $=2$, No help $=3$ \\
\hline Y & $\begin{array}{l}\text { The comprehensive score of community employment } \\
\text { intention }\end{array}$ & Very willing $=1$, Willing $=2$, Unwilling $=3$ \\
\hline
\end{tabular}

level with the help of the degree of" nine was statistically significant variables as independent variables, multiple linear regression analysis. Results showed that using variance analysis as a test of significance, $\mathrm{F}=27.05, \mathrm{P}<0.001$, the fitting equation was statistically significant. Results show that the senior medical students prefer to go to community employment, employment situation to judge the severe medical students prefer to go to community employment, salary expectations low medical students prefer to go to the grass-roots employment, to the community health service center (station) to understand how much medical students prefer to go to the grass-roots employment, school employment guidance at the grass-roots level to its help how much medical students prefer to grass-roots employment. General regression equation is: $\mathrm{Y}=20.216+0.156 \mathrm{X} 1+0.156 \mathrm{X} 3$ $\mathrm{X} 6$ by $8+1.689+1.689+0.523 \mathrm{X} 9$. Variable assignment is shown in Table 1, multiple linear analysis results are shown in Table 2 .

\section{DISSCUSS AND SUGGESTIONS}

\subsection{Community Health Service Center (Station)}

Community health service center (station) are the demand of talents, and its low wages material benefits, and problems such as poor career prospects, has been hampering the medical students are the important factors of community employment [2]. The conclusion of this survey to get the same proves this point. Can be seen from Fig. (1), "low community treatment, poor security", "community work environment is poor", "training, further education, continuing education opportunities such as less", "scientific research and academic community information block", "poor life monotonous community culture" is the main influencing factors of medical students to the community employment. So, the government should increase to the construction of community health service center (station), community health service center (station) to increase capital investment, optimize the 
Table 2. Multivariate regression analysis results of grass-roots employment intention.

\begin{tabular}{|c|c|c|c|c|c|}
\hline Influencing Factors & $\begin{array}{c}\text { Partial Regression } \\
\text { Coefficient }\end{array}$ & Standard Error & $\begin{array}{c}\text { The Standardized Partial } \\
\text { Regression Coefficient }\end{array}$ & The Value of T & The Value of P \\
\hline \hline Constant term & 20.216 & 0.975 & 20.892 & $<.501$ & $<0.001$ \\
\hline Grade (X1) & 0.156 & 0.032 & 0.215 & 4.785 & 3.107 \\
\hline $\begin{array}{c}\text { The employment situation judg- } \\
\text { ment (X3) }\end{array}$ & 0.298 & 0.051 & 0.198 & $<0.001$ \\
\hline $\begin{array}{c}\text { Salary expectation (X6) } \\
\text { health service center (station)(x8) }\end{array}$ & -0.523 & 0.212 & 0.258 & 5.893 & $<0.001$ \\
\hline $\begin{array}{c}\text { Degree of grass-roots employment } \\
\text { guidance with the help of the } \\
\text { school (X9) }\end{array}$ & 0.512 & 0.312 & 0.101 & 3.098 \\
\hline
\end{tabular}

allocation of health resources, improve the utilization rate of existing health resources, improve the level of community doctors pay [3]. At the same time, the government should establish the community doctor's training plan, strengthen continuing education training, in order to provide training, on-the-job graduate school for community doctor's long-term development plan.

\subsection{Schools}

Display in the linear regression equation, "to the community health service center (station) the understanding degree" and "school employment guidance to help the degree" and "community employment of medical graduates intention is positively related to the comprehensive score". This shows, medical students in Community Health Service Center (station) to know more, get the school to help more guidance on grass-roots employment, more willing to community health service center (station) employment. This school and some domestic research reported consistent [4] in education and guide the graduates to the grassroots employment can not shirk its responsibility to the conclusion. Therefore, the school should increase the community health service center (station) the introduction and propaganda work. Such as school please community health workers on community health service work at the school to carry out propaganda. And as the school organization for medical students to the community health service center (station) to carry out activities of social practice. At the same time, the school can be added on the grass-roots employment in employment guidance and social medical curriculum, especially the community health service center (station) the employment policy advocacy, employment psychology, interview skills and other related content.

\subsection{Medical Students Themselves}

\subsubsection{Understand the Severe Employment Situation}

Display in the linear regression equation, "employment situation judgment" and "community employment of medical graduates intention is positively related to the comprehensive score". That is to say, to judge the situation more severe employment of medical students, the community employment intention of higher. Therefore, to help medical students un- derstand the severe employment situation, can make the accurate positioning of their employment direction, so as to improve the medical students to the community health service center (station) the rate of employment.

\subsubsection{Decrease Employment Expectation}

Display in the linear regression equation, "salary expectations" and "community employment of medical graduates intention is negatively related to the comprehensive score". That is to say, the higher salary expectations of medical students, the community employment intention is low, this and a study concluded that "the student expectations too high leading to the grass-roots employment rate low" conclusion consistent [5]. Therefore, only decreasing employment expectation for medical students to work hard and perseveringly, do a good job in the ideological preparation, to volunteer to work in community health service.

\subsubsection{Establish a Correct Concept of Employment}

Investigation shows, the prompt medical students to each factors of community employment, medical students on "community itself development potential", "the community can exercise a person", "contributing to society of social return" factors such as the choice of rate of more than $50 \%$. In the way of medical students to various factors of community employment, medical students on "community employment can make family students to despise" the selection rate of $66.3 \%$ factors. This shows, establish a correct concept of employment to promote the employment of medical students has an important role in community. Therefore, medical students should combine the individual ideal and national, ethnic, the development of the times, to realize self value in the dedication, courage to the grass-roots level to exercise their own.

\section{CONFLICT OF INTEREST}

The authors confirm that this article content has no conflict of interest.

\section{ACKNOWLEDGEMENTS}

This paper is supported by Research project of Humanities and Social Sciences in the Ministry of Education, and by 
Social science development project of Hebei Province (2015031254), and by North China University of Science and Technology project (QZ1442-20, X2015250).

\section{REFERENCES}

[1] "National Health and Family Planning Committee of PRC," The Basic Conditions For Running Index Of Community Hospital, chapter 3, Beijing, 2004.
[2] H. Pan, "Time series analysis, p125,1st ed,' Beijing: Economic And Trade University Press, 2006.

[3] Y. Li, "The key contact city community health service institutions for human resource research, chapter 4, Master degree thesis," Huazhong University of Science and Technology, Hubei, 2008.

[4] "National Bureau of Statistics of PRC," Chinese health statistical yearbook, p356, China Statistics Press, Beijing, 2012.

[5] Chatfield, "The analysis of time series an introduction, p178," Fourth edition, Chapman and Hall. C., 1989.

(C) Bo et al.; Licensee Bentham Open.

This is an open access article licensed under the terms of the Creative Commons Attribution Non-Commercial License (http://creativecommons.org/licenses/by-nc/3.0/) which permits unrestricted, non-commercial use, distribution and reproduction in any medium, provided the work is properly cited. 